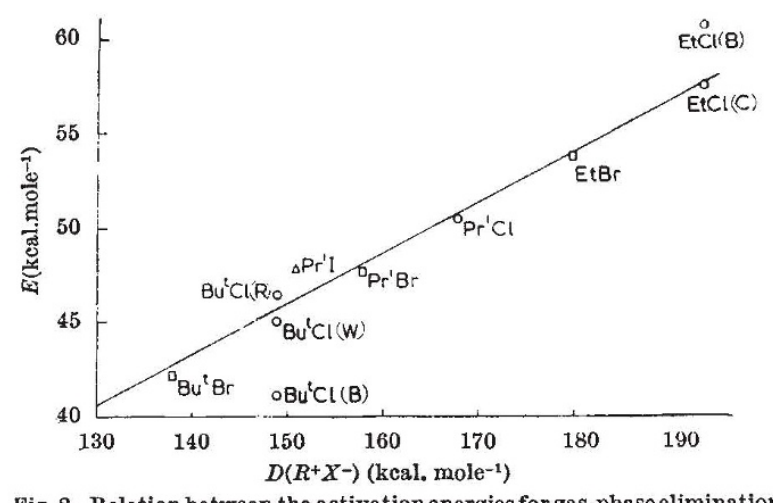

Fig. 8. Relation between the activation energies for gas-phase elimination and the heterolytic bond dissociation energies

There is one further aspect of Table 4 that I would like to mention in greater detail, namely, observation of Wagner-Meerwein rearrangements in the gas-phase. The first case reported was that of neopentyl chloride, in which it was shown that the major route of pyrolysis of this compound was a homogeneous, unimolecular one, the products being those that would have been expected from $t$-pentyl chloride. 'This again is analogous to the results:

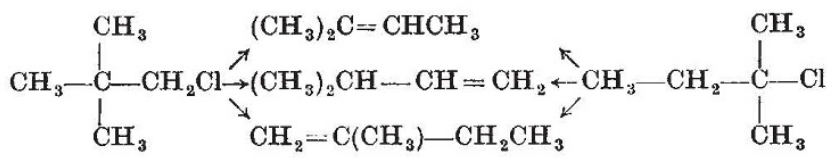
neopentyl chloride$$
+\mathrm{HCl}
$$

$t$-pentyl chloride

observed in the examination of the solvolysis of similar compounds. During the reaction, tho carbon skeleton has changed, which implies the migration of a methyl group from the $\beta$ - to the $\alpha$-carbon atom. Corresponding rearrangements have been observed in the gas-phase pyrolyses of bornyl and iso-bornyl chlorides, which again confirm the proposed analogy.

This then leads us to the main object of any kinetic study, namely, the molecular description of the process of reaction, or, more precisely, the assignment of a mechanism to the reaction or alternatively a physical model of the transition state. We have seen that those factors which lead to the stabilization of the carbonium ion also lead to an enhancement of the rate of gas-phase elimination. This, in turn, provides the essential clue to the mechanism. For it clearly suggests a carbonium ion character for the transition state. The essential experimental facts are in accord with the model of the transition state as an elongation, with polarization, of the $\mathrm{C}^{\delta+}-X^{\delta-}$ bond in the sense indicated. This in turn may be represented by the formula:

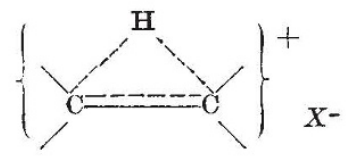

on the understanding that the charge separation has not been carried to completion, and further, that the system is stabilized by polarization forces. A somewhat better than order-of-magnitude calculation shows that such a formulation cannot be ruled out on energetic grounds.

This then is the position at which we stand at present. Gas-phase elimination reactions of the type I have discussed can be understood on the basis of the postulated transition state. In addition the correlation of tho solvolysis reaction in polar solvents with the gas-phase elimination reactions of the same compound can be rationalized on the basis of the gas-phase transition state prosented here. What still remains is a more detailed model for the transition state which will enable more precise estimates of rates of reaction to be made. This problem is a challenging one on which we hope eventually to throw more light.

What I have tried to do is to define what I understand to be physical chemistry, to outline the areas of mass spectrometry and gas-phase kinetics which we are investigating, and to indicate the progress which has been made up to the present time. In conclusion I should like to thank those people who have helped me at various stages. First, Prof. Fawsitt and Dr. Irodale of tho University of Sydney for encouraging my interest in chemistry and, secondly, the University of London for the award of an Imperial Chemical Industries fellowship. Thirdly, all my research associates, without whose help the work described here could not have been carried out. Finally, I would like to express my appreciation of the technical assistanco I have at all times received, of the support I have had from this College and of the advice $I$ have been given by colleagues past and present.

\title{
OBITUARY
}

\section{Prof. J. Bartels}

Prof. J. Bartels, professor of geophysies in the Univorsity of Göttingen, died on March 6.

Though deeply interested in all aspects of the physics of the Earth, and indeed much involved from time to time in seismology (results from Heligoland explosions) and meteorology (atmospheric tides and solar radiation), Bartels's life-long interest was in geomagnetism. In this discipline his early training at Potsdam Observatory under Dr. Adolph Schmidt ensured that he had the soundest possible basis on both observational practice and classical theory. One of his lasting contributions to the subject dates from that early period. He deduced from Prof. S. Chapman's analysis of the quict day solar and lunar magnetic variations the pattern of the electric current system in the atmosphere which could produce these variations. He also became much interested in the slow secular changes in the Earth's main magnetic field and brought out clearly the regional rather than planetary nature of this phenomenon. The recognition of this later led to the cause of the isoporic foci being attributed to fluid eddies in the Earth's core.
After Potsdam, Bartels spent several periods in the Department of Terrestrial Magnetism of the Carnegie Institution of Washington. There he had direct contact with the records from various observatories which the Institution had set up in specially selected parts of the World. The abnormally large daytime amplitude of the diurnal variation at Huancayo, Peru, attracted his attention and led him with colleagues in the Institution to make a series of detailed studies. These resulted in the discovery of what has become known as the equatorial electojet, a narrow band of intensified electric current in the high atmosphere over the magnetic equator, now explicable in terms of a steep increase in conductivity where the angle of inclination of the field is small.

To follow up his long-standing interest in relationships betwoen geomagnetic, solar and other related phenomena, Bartels needed an index of magnetic activity covering shorter intervals than the old international character figures for whole days; and, more particularly, he wanted the index to distinguish the effects of solar corpuscular radiation as shown by short-period irregular disturbance from the effects of electromagnetic wave radiation on the 
quiet day variation. The outcome of his work on this theme, which covered the period from before the Second World War to his later years, was the $3-\mathrm{h} K_{p}$ index, and, more experimentally, the 15 -min index $Q$. Thanks to its sound physical basis and the many careful investigations Bartels made to evaluate its validity and usefulness, $K_{p}$ is now internationally accepted in many geophysical disciplines as an authoritative index not just for geomagnetic activity but for comparison with all effects associated with the solar corpuscular wind.

In addition to his comprehensive grasp of the physics and mathematics of geomagnetism, Bartels had an exceptional flair for handling statistics and succinctly displaying their main import. His personal contributions to the subject in a series of papers on the harmonic dial, stereograms, harmonic analysis of a single day's data, and random fluctuations and persistence in quasi-periodicities have been adopted as present-day practice in many fields. $\mathrm{He}$ had a special and justifiable pride in the amount of concentrated information displayed in the 'musical diagrams' which he issued regularly from Göttingen to show the sequence, every three hours, of the planetary indices, $K_{p}$, over successive rotation intervals of the Sun.

In addition to his personal research work, the results of which appeared in a long series of papors, Bartels wrote several texts on magnetic observatory practice and the theory behind it: in 1940 with $\mathrm{S}$. Chapman he produced the two great volumes on geomagnetism which immediately became and still remain the definitive comprehensive text on the subject.

Since 1946 Bartels had held the joint posts of director of the Geophysical Observatory and professor of geophysics in the University of Göttingen. He took an active part in the international organizations related to his subjects, being president of the International Association of Geomagnetism and Aeronomy (1954-57), and vicepresident of International Union of Geodesy and Geophysics (1957-63), and chairman of various committees and commissions related to International Geophysical Year, International Year of the Quiet Sun and, more recently, the Committee on Space Research (COSPAR). In 1953 he was awarded the Charles Chree Medal by the London Physical Society. He was awarded posthumously the Bowie Medal by the American Geophysical Union. In recent years (since the death of Prof. Regener) he had been director of the Max Planck Gesellschaft Institute of Aeronomy at Lindau.

Bartels was a kindly, friendly man with a great fund of quiet humour and with catholic tastes in music and the arts.

\section{NEWS and VIEWS}

\section{Director of the Post Office Radio Services:}

Mr. H. G. Lillicrap

Mr. H. G. LiLlicrap has been appointed director of the Radio Services Department of the Post Office in succession to Mr. Alan Wolstencroft, who became deputy director general on August 15. Mr. Lillierap is at present a deputy director of finance in the Accountant General's Department at the Post Office. He started work in the Research Laboratories of the General Electric Co., Ltd., at Wembley, and joined the Post Office as a probationary assistant engineer in 1936. Apart from an early spell at Exeter, he spent most of the next ten years or so at the Post Office Research Station at Dollis Hill, London, working on the design of radio transmitters and receivers. In 1947 he moved to the Radio Branch of the Engineer-inChief's Department, where he was concerned with frequency allocation and the technical side of broadcasting. In 1951 he became a principal in what was then the Overseas Telecommunications Department (now the External Telecommunications Executive), of which he became a deputy director in 1958. While in this work he attended numerous international conferences at Buenos Aires, in the United States, Canada, Japan and various European countries. In 1960 he became a deputy director of finance.

\section{School of Applied Sciences in the University of Sussex:}

Prof. J. C. West

Prof. J. C. WEST, at present professor of electrical engineering in Queen's University of Belfast, has been appointed professor of engineering and dean of the School of Applied Sciences in the University of Sussex. Prof. West graduated at the University of Manchester in 1943 and then joined the Royal Navy Volunteer Reserve, being stationed in Northern Ireland for a period, engaged in anti-submarine warfare. He returned to the Electrical Engineering Department at Manchester in 1946, where he was appointed successively assistant lecturer, lecturer and senior lecturer. In 1958 he was appointed professor and head of the Department of Electrical Engineering in Queen's University of Belfast (Nature, 180, 1168; 1957), where he has been responsible for the rapid expansion of the Department. Prof. West is well known for his contributions to the analysis of non-linear servomechanisms, and for his more recent work on unconventional electrical machines. $\mathrm{He}$ is the author of two text-books on automatic control. As dean of the School of Applied Sciences in the new University of Sussex, Prof. West is eager to introduce undergraduate courses differing significantly from the traditional specialized subjects, and one of his first tasks is the specification of new buildings for engineers, the third time he has performed this operation.

\section{Electrical Power Engineering in the University of Southampton: \\ Prof. P. Hammond}

Mr. P. HAMmond, Fellow and director of studies in electrical sciences in Pembroke College, Cambridge, has been appointed to the chair of electrical power engineering at the University of Southampton. Mr. Hammond was educated at Steyning Grammar School and Emmanuel College, Cambridge. He served a graduate apprenticeship in electrical and mechanical engineering with the English Electric Co., Ltd., and afterwards joined the staff of this Company as a designer of synchronous machines. He was appointed to a lectureship at Cambridge in 1949 and was later elected to a fellowship at Pembroke College. He has twice been invited to servo as visiting professor overseas: at Stanford in 1955-56 and at Kuala Lumpur in 1962-63. Mr. Hammond is the author of a number of papers and one book on electromagnetism. His research work has been largely concerned with eddy current losses in rotating machines and he has written a number of articles on the early history of electromagnetism.

\section{Fibre Science in the University of Leeds :}

Prof. A. Robson

Dr. A. RoBson has been appointed professor of fibre science in the Department of Textile Industries in the University of Leeds as from September 1. After graduating from the University of Leeds in 1947, Dr. Robson worked under the late Prof. F. A. Paneth at the Londonderry Laboratories for Radiochemistry in the University of Durham, on the microanalysis of uranium. $\mathrm{He}$ was awarded a Ph.D. degree in 1949, and in the autumn of that year he joined the staff of the Wool Industries Research Association at Torridon, Leeds, as a senior scientific officer; latterly he has been head of the Fibre Chemistry Department. Dr. Robson's main interests have been in the application of radioisotope techniques 